\title{
Clinical presentation of eosinophilic esophagitis in the pediatric age
}

\author{
Adrián Chapa-Rodríguez ${ }^{1 *}$ and Diana Muñoz-Mendoza² \\ ${ }^{1}$ Department of Pediatric Gastroenterology, Hepatology, and Nutrition; ${ }^{2}$ Department of Allergy and Immunology. University of Arkansas for Medical \\ Sciences, Arkansas, United States of America
}

\section{Introduction and epidemiology}

Eosinophilic esophagitis (EoE) is a chronic clinical-pathological disease characterized by symptoms of esophageal dysfunction, such as dysphagia and globus, in addition of an inflammatory infiltration with $>15$ eosinophils per high-power field (eos/hpf), after having ruled out secondary causes of eosinophilia ${ }^{1}$.

The incidence and prevalence of this disease varies significantly from country to country. In an epidemiological study including several countries, they found a pooled incidence of 3.7/100,000/year, and a pooled of 22.7/100,000, however, there was significant heterogeneity in the information. On the other hand, when evaluating the presence of EoE in endoscopies performed for any indication, the incidence was 2.4-6.6\% ${ }^{2}$.

In Mexico, there are few epidemiological studies about EoE. De la Cruz-Patiño et al. ${ }^{3}$ conducted a cross sectional study in adults with dyspeptic symptoms who underwent an esophagogastroduodenoscopy (EGD), finding an incidence of $1.75 \%$. In another retrospective study, which included 4,700 endoscopies performed at referral center in Northeast Mexico, the EoE incidence was $0.76 \%{ }^{4}$. However, they only performed biopsies in $47 \%$ of patients. Therefore, the real incidence may be underestimated. Yu C. et al. studied the prevalence of EoE in Hispanic patients living in North America, finding a prevalence of $0.96 \%$ and $3.21 \%$ in El Paso, Tx, and Los Angeles, CA, respectively.

Interestingly enough, performing a specific genetic panel for EoE demonstrated that, at a genetic level, EoE prevalence is lower in Hispanic patients compared to Caucasians ${ }^{5}$. Brazil reported an EoE incidence in children similar to North America (5\%), with a preference toward males of 2.5:16.

In response to the lack of epidemiological knowledge of $\mathrm{EoE}$ in children, the Latin American Society for Pediatric Gastroenterology, Hepatology, and Nutrition (LASPGHN) conducted a multicenter study including 36 centers in Latin America, reporting a prevalence of $3.69 / 1,000$ visits to the outpatient clinic and $26 / 1,000$ EGD?

Undoubtfully, the chronicity and the associated costs with the management of this disease have caused an economic burden for patients and the healthcare system. Specifically in the United States, this cost has been estimated to be as high as 1.36 billion dollars a year $^{8}$. EoE management is substantially more expensive compared to Crohn and celiac diseases, especially in the outpatient setting. Moreover, there is a greater cost associated in the management of children compared to adults with $\mathrm{EoE}^{9}$.

\section{Correspondence:}

*Adrián Chapa-Rodríguez

E-mail: achaparodriguez@uams.edu
Date of reception: 31-10-2020

Date of acceptance: 02-11-2020 DOI: 10.24875/RMU.M20000054
Available online: $24-12-2020$

Medicina Universitaria. 2020;22(4):197-202 www.medicinauniversitaria.org

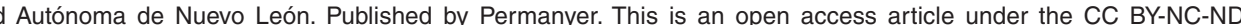
license (http://creativecommons.org/licenses/by-nc-nd/4.0/). 


\section{Pathophysiology}

EoE is a chronic inflammatory disease of Th2 lymphocyte predominance, characterized by an increase in the number of eosinophils in the esophageal mucosa. Multiple studies have proved the role of food as a cause of EoE in children and adults, after successful resolution of eosinophilic inflammation when elimination diet was instituted. This improvement reaches up to $90 \%$ with elemental diet ${ }^{10,11}$ and $72 \%$ with 6 food elimination diet (milk, eggs, wheat, soy, peanuts/tree nuts, and fish/shellfish) ${ }^{12}$.

However, these interventions are not effective in all patients, which suggests other possible causes. Pollens have also been implicated in EoE pathogenesis, which could result from cross-reactivity with certain food allergens ${ }^{13,14}$.

Multiple cytokines are elevated in the esophagus of patients with EoE, including Th2 cytokines (IL-4, IL-5, and IL-13), as well as TSLP (Thymic stromal lymphopoietin), IL-33 and other ${ }^{15}$. Understanding the role of these cytokines has implications in the treatment of this disease. IL-5 promotes eosinophilia in the esophageal mucosa, an effect that is evident with the significant histological improvement of patients treated with humanized monoclonal antibody anti-IL-5 compared to placebo. Nevertheless, these studies did not demonstrate improvement in clinical symptoms ${ }^{16}$. IL-13, produced by Th2 lymphocyte cells and activated eosinophils, plays a major role in disruption of the epithelial barrier integrity ${ }^{15}$. Additionally induces tissue remodeling by promoting collagen deposition and epithelial hyperplasia, wich occurs independently to eosinophilia ${ }^{17}$. EoE treatment studies with anti-IL-13 showed improvement in esophageal eosinophilia and its symptoms ${ }^{18}$.

It is unclear if IgE plays a role in the pathogenesis of EoE. Patients with EoE commonly have elevated specific IgE and positive skin testing to allergens, however $\mathrm{IgE}$ production is not necessarily required to induce $\mathrm{EoE}$ as is demostrate in animal models ${ }^{19,20}$. Also, studies with anti-lgE have not been proved to reduce esophageal eosinophilia ${ }^{21}$.

\section{Atopy in EoE}

The association between EoE and atopic diseases (asthma, allergic rhinitis, atopic dermatitis, IgE-mediated food allergies, and pollen-food allergy syndrome) has been well established in different studies ${ }^{22-24}$, and has been suggested that EoE could be a late manifestation

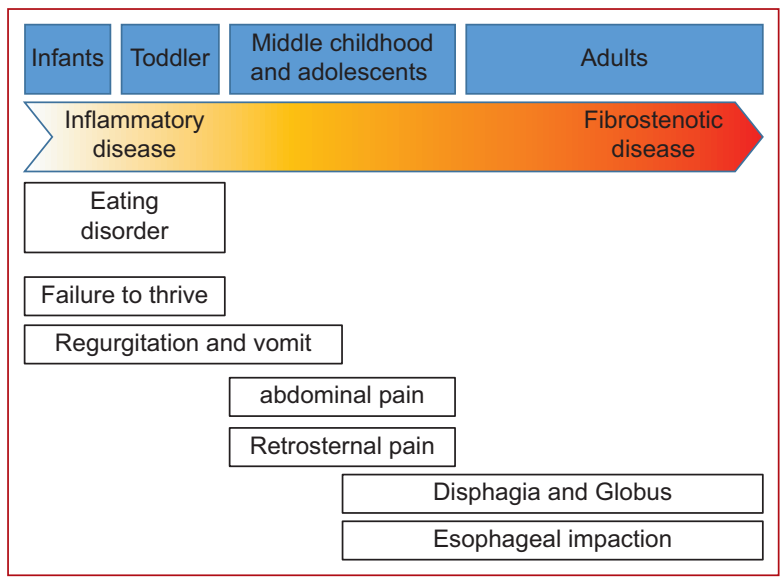

Figure 1. Difference in the clinical presentation between children and adults with EoE. Adapted from: MunozMendoza et al. ${ }^{38}$

of the atopic march ${ }^{25}$. Several studies demonstrate a high frequency of positive tests for food allergies in patients with EoE, in serum, and skin prick tests, espe-

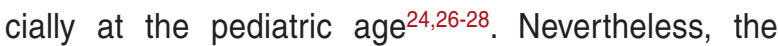
usefulness of food tests to direct elimination diets in EoE remains controversial.

Patients with EoE also have higher rates of positive tests to aeroallergens compared to the general population, being $44-46 \%$ through serum specific IgE testing and $71-93 \%$ through skin tests ${ }^{29}$.

\section{Clinical presentation}

\section{Risk factors}

EoE is a complex, multifactorial disease, where genetic factors, history of atopic diseases, early exposure to antibiotics, use of proton-pump inhibitors (PPI), and passive smoking are some of the risk factors associated with $\mathrm{EoE}^{30-32}$.

\section{Clinical presentation}

The clinical presentation depends on the patient's age (Fig. 1) and his/her ability to communicate obstructive and irritative esophageal symptoms ${ }^{33}$. Adolescents behave more like the adult population, where dysphagia and globus are the predominant symptoms. Infants and preschoolers may present most commonly with reflux symtoms, vomiting, choking, and feeding dysfunction (FD) (Table 1) and should alert the clinician about possible dysphagia in this age group ${ }^{34-38}$. 
In a retrospective study in patients with eosinophilic gastrointestinal disorders (EGIDs), Mukkada et al. found $17 \%$ of patients had FD, $93 \%$ had learned maladaptive feeding behaviors, followed by vomiting, nausea, and choking in $85 \%{ }^{39}$. A similar study proved that $\mathrm{FD}$, in addition to occurring at an earlier age $(<7$ years of age), tends to be more severe and linked with greater stress in parents ${ }^{40}$.

Mehta et al. studied prospectively the characteristics of FD in children under 7 years of age with gastroesophageal reflux diseases and EoE. An abnormal feeding behavior characterized by requiring over 20 min to finish their meals, preferring liquids rather than solid foods, and "negotiating" the type of foods they preferred to eat was found in both pathologies ${ }^{41}$. Interestingly, EoE treatment with elimination diets improved FD in patients with EoE.

Other symptoms commonly reported are abdominal pain, retrosternal pain, early satiety, loss of appetite, regurgitation, and dyspepsia. Patients with EoE presenting with abdominal pain as a cardinal symptom seem to have a different clinical behavior from those with dysphagia, as a study by Gunasekaran et al. suggests ${ }^{42}$. This study showed that the classic endoscopic changes are more frequent in patients with dysphagia and have a better response to treatment than those with abdominal pain. However, symptoms can also be underestimated due to its chronicity and the adaptation behavior developed by patients with dysphagia ${ }^{33,43}$. (Table 2).

The dissociation between symptoms and disease activity has been described. Pentiuk et al. ${ }^{44}$ created a clinical instrument to evaluate symptoms in children with EoE, the Pediatric Eosinophilic Esophagitis Symptom Score, (PEESS). They did not find a correlation between symptoms and esophageal eosinophilia. Additonally, $88 \%$ of patients in remission reported persistent abdominal pain.

In 2011, Francoisi et al. ${ }^{45}$ developed and validated the new version of PEESS (PEESS v2.0) which was written in order for patients or parents to answer the questionnaire. It also incorporates descriptive questions to better assess dysphagia in children.

Martin et al. ${ }^{46}$ used the PEESS v2.0 to evaluate the different symptoms with histological and genetic findings in pediatric patients with EoE. Despite having a small sample, exclusively Caucasian males, there are several significant findings worth highlighting. The first one is that the PEESS $\vee 2.0$ has an intrinsic validity. Secondly, there was a positive correlation between dysphagia and the eosinophil derived
Table 1. Clinical presentation of feeding dysfunction in children

Dysphagia or discomfort in the esophageal phase of swallowing

Food refusal or oral aversion

Decrease in quantity and variety of foods accepted

Coughing during swallowing, vomiting, or a choking sensation

Delay in the acquisition of mature eating patterns

Delay in acquiring skills to eat independently

Chronic pain or discomfort associated with food or mealtime

Learned behavioral or eating problems

Compromised nutritional status

Table 2. Adaptive behavior in patients with dysphagia

Prolonged time to eat, eats more slowly than the rest of the family

Retention of food in the mouth

Prolonged chewing

Drink water after each bite to dilute the bolus

Cut the food into smaller pieces

Lubricate food with sauces or dressings

Avoid foods with a hard or dry consistency. Avoid pill/tablet medications

peroxidase, and proximal esophageal eosinophilia. Third, there was a significant difference between patients with active and inactive disease at the genetic level.

In general, we conceptualize the behavior of this disease as an inflammatory or fibro-stenotic process. But far from being a dichotomic reality, it is more a progression or a spectrum of severity. A retrospective study conducted in the Netherlands that included children and adults found that the risk of presenting esophageal stenosis or food bolus impaction was $9 \%$ for every year that the patient remains without a diagnosis ${ }^{47}$.

\section{Diagnosis}

\section{Endoscopy}

The endoscopy plays a major role in the diagnosis and follow-up of this disease. The description of endoscopic findings has been standardized using a 
validated instrument [EoE Endoscopic Reference Score (EREFS)]. It evaluates the presence and severity of different inflammatory (furrows, exudates, and edema) and fibro-stenotic (stenosis, rings/ridges, and crêpe-paper mucosa) findings of $E_{0} E^{48}$. The presence of more than one finding in the EREFS during a diagnostic endoscopy has a sensitivity of $90 \%$ and a specificity of $88 \%$ for identifying patients with $\mathrm{EoE}^{49}$.

Without a doubt, patients with EoE will require a greater number of endoscopies throughout their lives, exposing them to more anesthetics, school/work absenteeism, and an economic burden for patients/families. Trans-nasal esophagoscopies without sedation have emerged as a response to this concern. This modality of endoscopy has been linked to greater satisfaction in patients and their parents, have been able to obtaining similar biopsies to those obtained during a EGD and is associated with $62 \%$ reduction of costs $^{50,51}$.

EoE diagnosis is based on clinical presentation in combination with the histological changes, which are characteristic of this disease (> 15 eos/hpf). In 2018, new guidelines were published for the diagnosis of EoE. It has simplified the approach of patients under suspicion of EoE, since the esophageal eosinophilia responsive to PPI is considered part of the EoE spectrum rather than being a factor which discriminates between reflux and $\mathrm{E}^{1} \mathrm{E}^{1}$. The list of differential diagnoses to consider is described in Table 3.

\section{Image studies}

A barium esophagogram, despite having a low diagnostic sensitivity in childrens ${ }^{52}$, can provide complementary information to the endoscopy, particularly to evaluate fibro-stenotic complications (i.e., rings, stenosis, and small caliber esophagus $)^{53}$. It can be a useful study, especially in those patients with a normal endoscopy and persistent dysphagia. Diniz et al. ${ }^{54}$ found that despite half of the esophagograms performed in patients with EoE being normal, $25 \%$ of these had fibro-stenotic complications. On the other hand, endoscopy alone can overlook half of the esophageal stenosis in children ${ }^{55}$. Similarly, in adults, it was proved that the sensitivity of detecting esophageal stenosis $<13 \mathrm{~mm}$ through endoscopy is $26 \%{ }^{56}$.

\section{Cytosponge ${ }^{\circledast}$}

The Cytosponge ${ }^{\circledR}$ is a $3 \mathrm{~cm}$ spherical polyurethane sponge wrapped with a gel capsule, wich has a string.
Table 3. Differential diagnosis of eosinophilic esophagitis

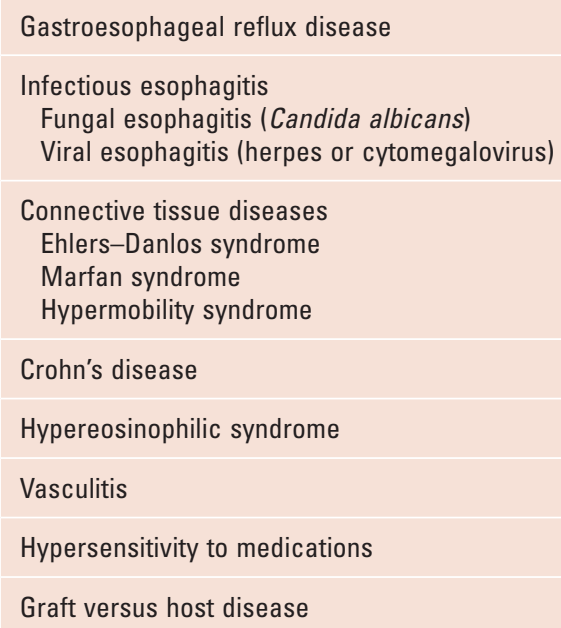

After swallowing the capsule, it will dissolve inside the stomach, releasing the sponge. With gentle traction of the string, the sponge is retrieved until it comes out through the mouth. During its path through the esophagus, the sponge obtains a sample of the esophageal epithelium for cytological analysis, focus on the detection of esophageal cancer or Barrett's esophagus.

In a viability study, Katzka et al. compared the sample obtained by the Cytosponge versus other biopsies obtained during an EGD. The sensitivity was $85 \%$, and specificity was $56 \%$ to detect $>15$ eosinophils per high-power field ${ }^{57}$. A subsequent study proved that eosinophils obtained with the Cytosponge are strongly correlated with those obtained through an endoscopic biopsy. Moreover, it is a minimally invasive, safe, and well-tolerated procedure ${ }^{58}$. There have not been any similar studies conducted in patients under 18 years of age for the time being.

\section{String test}

The string test, or Entero-test, is a device consisting of a capsule that releases a string in the duodenum to identify pathogens. In 2013, Furuta et al. ${ }^{59}$ utilized this device to measure products derived from the eosinophils as a minimally invasive method to evaluate EoE activity. Pediatric patients were included in this study. Findings showed that the string test was able to differentiate between patients with active/inactive EoE gastroesophageal reflux, and a normal esophagus. Recently, a multi-center, prospective study assessed the use of the string test in children and adults with EoE, but with a period of string retention of 1 
hour instead of the 16 hours of the original study. The hour-long string test was capable of distinguishing between active and EoE in remission in children and adults $^{60}$.

\section{Conclusion}

EoE is a chronic inflammatory disease of the esophagus, with the potential of progressing to a fibrostenotic phenotype. The It's etiology is multifactorial, yet with a clear atopic footprint. Its clinical presentation varies with age and is characterized by esophageal dysfunction symptoms. To reach a diagnosis, clinical suspicion together with characteristic histological and endoscopic findings are required.

\section{Conflicts of interest}

The authors have no conflicts of interest to declare.

\section{References}

1. Dellon ES, Liacouras CA, Molina-Infante J, Furuta GT, Spergel JM Zevit $\mathrm{N}$, et al. Updated international consensus diagnostic criteria for eosinophilic esophagitis: proceedings of the AGREE conference. Gastroenterology. 2018;155:1022-33.e10.

2. Dellon ES, Hirano I. Epidemiology and natural history of eosinophilic esophagitis. Gastroenterology. 2018;154:319-32.e3.

3. de la Cruz-Patino E, Juarez IR, Daza AM, Pagola PG, Roesch-Dietlen F, Remes-Troche JM. Eosinophilic esophagitis prevalence in an adult population undergoing upper endoscopy in Southeastern Mexico. Dis Esophagus. 2015;28:524-9.

4. Garcia-Compean D, Gonzalez-Gonzalez JA, Duran-Castro JJ, et al. Low prevalence of biopsy-proven eosinophilic esophagitis in patients with esophageal food impaction in Mexican population. Dig Dis Sci. 2018;63:1506-12.

5. Yu C, Sterling D, Albayati I, Al-Obaidi S, Moraveji S, Bustamante MA et al. The prevalence of biopsy-proven eosinophilic esophagitis in hispanics undergoing endoscopy is infrequent compared to caucasians: a cross-sectional study. Dig Dis Sci. 2017;62:3511-6.

6. Strozzi D, Botacin MA, Mekdessi MA, Salustiano LX, Silva PH, Minasi LB, et al. Frequency of esophageal eosinophilia in a pediatric population from Central brazil. Sci Rep. 2018;8:5000.

7. Pierre R, Vieira M, Vazquez R, Ninomiya I, Messere G, Daza W, et al. Prevalence of eosinophilic esophagitis: a multicenter study on a pediatric population evaluated at thirty-six Latin American gastroenterology centers. Rev Gastroenterol Mex. 2019;84:427-33.

8. Jensen ET, Kappelman MD, Martin CF, Dellon ES. Health-care utilization, costs, and the burden of disease related to eosinophilic esophagitis in the United States. Am J Gastroenterol. 2015;110:626-32.

9. Anderson J, Moonie S, Hogan MB, Scherr R, Labus B, Word J. Cost of chronic inflammatory disease: the impact of eosinophilic esophagitis in Nevada. J Dig Dis. 2020;21:12-9.

10. Peterson KA, Byrne KR, Vinson LA, Ying J, Boynton KK, Fang JC, et al. Elemental diet induces histologic response in adult eosinophilic esophagitis. Am J Gastroenterol. 2013;108:759-66.

11. Kelly KJ, Lazenby AJ, Rowe PC, Yardley JH, Perman JA, Sampson HA Eosinophilic esophagitis attributed to gastroesophageal reflux: improvement with an amino acid-based formula. Gastroenterology. 1995;109:1503-12.

12. Arias A, Gonzalez-Cervera J, Tenias JM, Lucendo AJ. Efficacy of dietary interventions for inducing histologic remission in patients with eosinophilic esophagitis: a systematic review and meta-analysis. Gastroenterology. 2014;146:1639-48.

13. Moawad FJ, Veerappan GR, Lake JM, Maydonovitch CL, Haymore BR, Kosisky SE, et al. Correlation between eosinophilic oesophagitis and aeroallergens. Aliment Pharmacol Ther. 2010;31:509-15.

14. van Rhijn $B D$, van Ree $R$, Versteeg $S A$, Vlieg-Boerstra $B J$, Sprikkelman AB, Terreehorst I, et al. Birch pollen sensitization with cross-reactivity to food allergens predominates in adults with eosinophilic esophagitis. Allergy. 2013;68:1475-81.
15. Davis BP. Pathophysiology of eosinophilic esophagitis. Clin Rev Allergy Immunol. 2018;55:19-42.

16. Fulkerson PC, Rothenberg ME. Targeting eosinophils in allergy, inflammation and beyond. Nat Rev Drug Discov. 2013;12:117-29.

17. Zuo L, Fulkerson PC, Finkelman FD, Mingler M, Fischetti CA, Blanchard C, et al. IL-13 induces esophageal remodeling and gene expression by an eosinophil-independent, IL-13R alpha 2-inhibited pathway. J Immunol. 2010;185:660-9.

18. Rothenberg ME, Wen T, Greenberg A, Alpan O, Enav B, Hirano I, et al. Intravenous anti-IL-13 mAb QAX576 for the treatment of eosinophilic esophagitis. J Allergy Clin Immunol. 2015;135:500-7.

19. Noti M, Wojno ED, Kim BS, Siracusa MC, Giacomin PR, Nair MG, et al. Thymic stromal lymphopoietin-elicited basophil responses promote eosinophilic esophagitis. Nat Med. 2013;19:1005-13.

20. Mishra A, Schlotman J, Wang M, Rothenberg ME. Critical role for adaptive $T$ cell immunity in experimental eosinophilic esophagitis in mice. $J$ Leukoc Biol. 2007;81:916-24.

21. Rocha R, Vitor AB, Trindade E, Lima R, Tavares M, Lopes J, Dias JA. Omalizumab in the treatment of eosinophilic esophagitis and food allergy. Eur J Pediatr. 2011;170:1471-4.

22. Capucilli P, Hill DA. Allergic comorbidity in eosinophilic esophagitis: mechanistic relevance and clinical implications. Clin Rev Allergy Immunol. 2019;57:111-27.

23. Rezende ER, Barros CP, Ynoue LH, Santos AT, Pinto RM, Segundo S. Clinical characteristics and sensitivity to food and inhalants among children with eosinophilic esophagitis. BMC Res Notes. 2014;7:47.

24. Roy-Ghanta S, Larosa DF, Katzka DA. Atopic characteristics of adult patients with eosinophilic esophagitis. Clin Gastroenterol Hepatol. 2008; 6:531-5.

25. Hill DA, Grundmeier RW, Ramos M, Spergel JM. Eosinophilic esophagitis is a late manifestation of the allergic March. J Allergy Clin Immunol Pract. 2018:6:1528-33.

26. Erwin EA, James HR, Gutekunst HM, Russo JM, Kelleher KJ, Platts-Mills TA. Serum IgE measurement and detection of food allergy in pediatric patients with eosinophilic esophagitis. Ann Allergy Asthma Immunol. 2010;104:496-502.

27. Spergel JM, Beausoleil JL, Mascarenhas M, Liacouras CA. The use of skin prick tests and patch tests to identify causative foods in eosinophilic esophagitis. J Allergy Clin Immunol. 2002;109:363-8.

28. Penfield JD, Lang DM, Goldblum JR, Lopez R, Falk GW. The role of allergy evaluation in adults with eosinophilic esophagitis. J Clin Gastroenterol. 2010;44:22-7.

29. Liacouras CA, Furuta GT, Hirano I, Atkins D, Attwood SE, Bonis PA, et al. Eosinophilic esophagitis: updated consensus recommendations for children and adults. J Allergy Clin Immunol. 2011;128:3-20.e6; quiz 21-2.

30. Kottyan LC, Parameswaran S, Weirauch MT, Rothenberg ME, Martin LJ. The genetic etiology of eosinophilic esophagitis. J Allergy Clin Immunol. 2020;145:9-15.

31. Slae M, Persad R, Leung AJ, Gabr R, Brocks D, Huynh HQ. Role of environmental factors in the development of pediatric eosinophilic esophagitis. Dig Dis Sci. 2015;60:3364-72.

32. Witmer CP, Susi A, Min SB, Nylund CM. Early infant risk factors for pediatric eosinophilic esophagitis. J Pediatr Gastroenterol Nutr. 2018;67:610-5.

33. Lucendo AJ, Sanchez-Cazalilla M. Adult versus pediatric eosinophilic esophagitis: important differences and similarities for the clinician to understand. Expert Rev Clin Immunol. 2012;8:733-45.

34. Markowitz JE, Clayton SB. Eosinophilic esophagitis in children and adults. Gastrointest Endosc Clin N Am. 2018;28:59-75

35. Hommeida S, Grothe RM, Hafed Y, Lennon RJ, Schleck CD, Alexander JA, et al. Assessing the incidence trend and characteristics of eosinophilic esophagitis in children in Olmsted county, Minnesota. Dis Esophagus. 2018;31:doy062.

36. Spergel J, Brown-Whitehorn TF, Beausoleil JL, Franciosi J, Shuker M, Verma R, et al. 14 Years of eosinophilic esophagitis: clinical features and prognosis. J Pediatr Gastroenterol Nutr. 2009;48:30-6.

37. Haas AM, Maune NC. Clinical presentation of feeding dysfunction in children with eosinophilic gastrointestinal disease. Immunol Allergy Clin North Am. 2009;29:65-75, 9.

38. Munoz-Mendoza D, Chapa-Rodriguez A, Bahna SL. Eosinophilic esophagitis clinical manifestations and differential diagnosis. Clin Rev Allergy Immunol. 2018:55:7-18.

39. Mukkada VA, Haas A, Maune NC, Capocelli KE, Henry M, Gilman N et al. Feeding dysfunction in children with eosinophilic gastrointestinal diseases. Pediatrics. 2010;126:e672-7.

40. Wu YP, Franciosi JP, Rothenberg ME, Hommel KA. Behavioral feeding problems and parenting stress in eosinophilic gastrointestinal disorders in children. Pediatr Allergy Immunol. 2012;23:730-5.

41. Mehta P, Furuta GT, Brennan T, Henry ML, Maune NC, Sundaram SS, et al. Nutritional state and feeding behaviors of children with eosinophilic esophagitis and gastroesophageal reflux disease. J Pediatr Gastroenterol Nutr. 2018;66:603-8. 
42. Gunasekaran T, Prabhakar G, Schwartz A, Gorla K, Gupta S, Berman J. Eosinophilic esophagitis in children and adolescents with abdominal pain: comparison with EoE-dysphagia and functional abdominal pain. Can $\mathrm{J}$ Gastroenterol Hepatol. 2016;2016:4123692.

43. Furuta GT, Katzka DA. Eosinophilic esophagitis. N Engl J Med. 2015;373:1640-8.

44. Pentiuk S, Putnam PE, Collins MH, Rothenberg ME. Dissociation between symptoms and histological severity in pediatric eosinophilic esophagitis. J Pediatr Gastroenterol Nutr. 2009;48:152-60.

45. Franciosi JP, Hommel KA, DeBrosse CW, Greenberg AB, Greenler AJ, Abonia JP, et al. Development of a validated patient-reported symptom metric for pediatric eosinophilic esophagitis: qualitative methods. BMC Gastroenterol. 2011;11:126.

46. Martin LJ, Franciosi JP, Collins MH, Abonia JP, Lee JJ, Hommel KA, et al. Pediatric eosinophilic esophagitis symptom scores (PEESS v2.0) identify histologic and molecular correlates of the key clinical features of disease. J Allergy Clin Immunol. 2015;135:1519-28.e8.

47. Warners MJ, Nijhuis RA, de Wijkerslooth LR, Smout AJ, Bredenoord AJ. The natural course of eosinophilic esophagitis and long-term consequences of undiagnosed disease in a large cohort. Am J Gastroenterol. 2018;113:836-44

48. Hirano I, Moy N, Heckman MG, Thomas CS, Gonsalves N, Achem SR, et al. Endoscopic assessment of the oesophageal features of eosinophilic oesophagitis: validation of a novel classification and grading system. Gut. 2013:62:489-95.

49. Wechsler JB, Bolton SM, Amsden K, Wershil BK, Hirano I, Kagalwalla AF. Eosinophilic esophagitis reference score accurately identifies disease activity and treatment effects in children. Clin Gastroenterol Hepatol. 2018;16:1056-63.

50. Friedlander JA, DeBoer EM, Soden JS, Furuta GT, Menard-Katcher CD Atkins $D$, et al. Unsedated transnasal esophagoscopy for monitoring therapy in pediatric eosinophilic esophagitis. Gastrointest Endosc. 2016; 83:299-306.e1.
51. Nguyen N, Lavery WJ, Capocelli KE, Smith C, DeBoer EM, Deterding R, et al. Transnasal endoscopy in unsedated children with eosinophilic esophagitis using virtual reality video goggles. Clin Gastroenterol Hepatol. 2019;17:2455-62.

52. Binkovitz LA, Lorenz EA di Lorenzo C, Kahwash S. Pediatric eosinophilic esophagitis: radiologic findings with pathologic correlation. Pediatr Radiol. 2010;40:714-9.

53. Menard-Katcher C, Swerdlow MP, Mehta P, Furuta GT, Fenton LZ Contribution of esophagram to the evaluation of complicated pediatric eosinophilic esophagitis. J Pediatr Gastroenterol Nutr. 2015;61:541-6.

54. Diniz LO, Putnam PE, Towbin AJ. Fluoroscopic findings in pediatric eosinophilic esophagitis. Pediatr Radiol. 2012:42:721-7.

55. Menard-Katcher C, Swerdlow MP, Mehta P, Fenton LZ. Contribution of esophagram to the evaluation of complicated pediatric eosinophilic esophagitis. J Pediatr Gastroenterol Nutr 2015;61:541-546.

56. Gentile N, Katzka DA, Ravi K, Trenkner S, Enders F, Killian J, et al. Oesophageal narrowing is common and frequently under-appreciated at endoscopy in patients with oesophageal eosinophilia. Aliment Pharmacol Ther. 2014;40:1333-40.

57. Katzka DA, Geno DM, Ravi A, Smyrk TC, Lao-Sirieix P, Miremadi A, et al. Accuracy, safety, and tolerability of tissue collection by cytosponge vs endoscopy for evaluation of eosinophilic esophagitis. Clin Gastroenterol Hepatol. 2015;13:77-83.e2.

58. Katzka DA, Smyrk TC, Alexander JA, Geno DM, Beitia RA, Chang AO, et al. Accuracy and safety of the cytosponge for assessing histologic activity in eosinophilic esophagitis: a two-center study. Am J Gastroenterol. 2017;112:1538-44.

59. Furuta GT, Kagalwalla AF, Lee JJ, Alumkal P, Maybruck BT, Fillon S, et al. The oesophageal string test: a novel, minimally invasive method measures mucosal inflammation in eosinophilic oesophagitis. Gut. 2013; 62:1395-405.

60. Ackerman SJ, Kagalwalla AF, Hirano I, Gonsalves N, Katcher PM, Gupta S, et al. One-hour esophageal string test: a nonendoscopic minimally invasive test that accurately detects disease activity in eosinophilic esophagitis. Am J Gastroenterol. 2019;114:1614-25. 